\title{
Research on Rural Logistics Development Strategy and Construction of Common Logistics System in Hunan*
}

\author{
Shijun Yuan \\ Hunan Modern Logistics College \\ Changsha, China
}

\author{
Jianhua Chen** \\ Hunan Modern Logistics College \\ Changsha, China \\ **Corresponding Author
}

\begin{abstract}
Currently, there are many problems in the development of rural logistics in Hunan, such as lack of investment in logistics facilities and equipment, low level of informatization, personnel quality to be improved, etc. This paper analyzes the current situation of logistics enterprises and their development opportunities in the environment of Internet of things, presents the development strategy of rural logistics in Hunan under the Internet of things environment and constructs a common logistics system in Hunan rural areas.
\end{abstract}

Keywords - the Internet of things; chain logistics; common logistics; development strategy

\section{INTRODUCTION}

At present, there is a serious shortage of logistics facilities and equipment in the development of rural logistics in Hunan province. The leased waste factory or warehouse is simply transformed into a "distribution center". The center is equipped with simple logistics equipment with single logistics functions and a focus of storage services. Insufficient integration and utilization of resources, low level of mechanization and modernization, lack of use of modern RFID and other Internet of things technologies to monitor and manage the whole process of logistics, lack of professional logistics information system to support its logistics big data analysis, absence of effective integration of logistics resources between supply chain member enterprises, and less collaborative operation of logistics cause the idle and waste of logistics resources and other outstanding problems, which needs to be solved urgently.

\section{DEVELOPMENT OPPORTUNITIES AND APPLICATION}

BOTTLENECKS OF RURAL LOGISTICS IN HUNAN PROVINCE

\section{A. Development Opportunities}

As one of the five strategic emerging industries, the Internet of things has been lifted up to the national strategic

*Fund: 2018 Hunan philosophy and social science fund base project "Research on the Establishment of Rural Logistics System in Hunan Province Based on the Strategy of Rural Revitalization" (18JD43) and the phased research result of Hunan Social Science Achievement Review Committee "Research on the Countermeasure System of Rural Logistics Development Based on the Strategy of Rural Revitalization" (XSP19YBC277). level. Local governments across China have formulated policies to advance and support the development of the Internet of things, and quite a few cities have set up research centers for Internet of things technology to facilitate its wide application in various industries. For the rural logistics industry in Hunan, the application of Internet of things technology will effectively make the industry more competitive.

1) The application of RFID tags will improve the amount of information and security of goods: RFID tags are used for logistics goods, which can store more information related to the goods, have strong anti-interference, security and confidentiality, and can be reused and more environmental protection. The use of RFID tags can also monitor and track the entire supply chain of logistics goods.

2) The application of Internet of things technology will effectively enhance the efficiency of logistics operation: In the distribution link, the Internet of things technology can automatically obtain the information of goods in and out of the distribution, which raises the delivery speed and sorting efficiency of the whole supply chain.

In the transportation of logistics goods, goods and vehicles in transit are labeled with electronic tags. The fixed-point readers laid on the roadside can read and write information, and transmit the information to the dispatching center through the communication satellite, so as to dynamically track the whole transportation process of goods.

In the storage link, the Internet of things technology can improve the inventory management of logistics providers, help them to replenish goods in time, and reduce manpower and error rate in the inventory check of warehouse goods in order to improve efficiency. It also can effectively track transportation and inventory, monitor the expiration date of goods by using electronic tags, and realize automatic scanning charge when paying, which greatly lowers the labor cost in the logistics industry and increases the efficiency of enterprises.

3) The application of Internet of things technology will promote customer satisfaction: The supply chain of logistics industry based on Internet of things technology promotes customer satisfaction, which is the ultimate goal of supply 
and some problems in the RFID chip's adaptation to antennas and wireless networks.

cornerstone of the development of logistics enterprises and the engine of enterprise growth. The reconstruction and design of the flow of supply chain exerts an irreplaceable positive role in raising enterprise management level, management quality and management process. In the meantime, with the development, expansion and maturity of Internet of things technology in the supply chain process of logistics enterprises, the systematic and standardized quality of enterprise management will be greatly increased. The integration of supply chain by using the Internet of things technology will greatly reduce the transaction cost of each link, and shorten the transaction time. What's more, the automation of supply chain and accuracy of prediction will be greatly improved, so that enterprises not only can produce the required products, but also can decrease the production time and greatly expand the network.

\section{B. Application Bottlenecks}

1) No unified RFID technology standard for the field of common logistics of rural logistics service demanders in Hunan Province: The implementation of the common logistics of Hunan rural logistics service demanders requires the real-time collection and synchronous update of information in the whole process of supply chain. However, China has not yet executed a unified plan on the standards of the Internet of things technology. In terms of RFID technology, efforts are still needed to develop advanced technologies, break through bottlenecks, and further expand the development of the Internet of things technology in the field of chain retail and common logistics.

2) Various enterprise standards for rural logistics in Hunan province: In the chain retail industry, most leading enterprises independently cooperate with Internet of things technology and equipment suppliers according to the actual needs of their own enterprises, and use the Internet of things technology and equipment tailored for their own enterprise. This condition has produced various standards, and the data cannot be shared between enterprises.

3) Extensively existed information sharing barrier: The implementation of common logistics of rural logistics service demanders in Hunan province needs to break through the existing barriers between the demanders and upstream and downstream firms, between the demanders themselves, and between systems and systems of enterprise, and to break the obstacles between chain retail industry and logistics industries and regions, which is a problem that needs to be solved in the large-scale application of the Internet of things in the supply chain.

4) Capability failure of internet of things technology service supplier: At present, the capabilities of China's Internet of things technology service supplier are relatively weak. There are inadequate investment in Internet of things infrastructures, the high cost of Internet of things equipment,

\section{COMMON LOGISTICS DEVELOPMENT STRATEGY OF CHAIN LOGISTICS INDUSTRY IN THE CONTEXT OF THE INTERNET OF THINGS}

\section{A. Applying Key Technology of Internet of Things Actively and Laying the Foundation of Common Logistics Development for the Chain Logistics Industry}

Logistics enterprises and upstream commodity suppliers reach an agreement on the Internet of things technology applications and common logistics strategic cooperative relationship. When products are produced at supplier factories, the key technology of Internet of things - RFID chip technology is used, which can not only collect information during production, but also can collect the production information about raw materials and semi-finished products. First, when logistics enterprises purchase this product, they can trace the series of information of upstream suppliers and raw material suppliers to ensure the quality of the products. Second, after the logistics company receives the product, it can collect and manage all data of the product in the whole process, and track in real time and dynamically grasp the position of the batch of products through real-time data transmission, which can provide relevant logistics partners of common logistics with relevant information and ensure seamless docking of logistics services. Third, it can also provide the final consumers with relevant information about the entire process of the commodity supply chain and realize the traceability for commodity production and logistics services.

\section{B. Designing and Developing a Common Logistics Management System Based on the Internet of Things}

The main structure of the common logistics management system based on the Internet of things mainly comprises the following parts:

1) Electronic data collection system of common logistics: The system is composed of the article and its corresponding electronic tag, reader, etc. Its main function is to identify the characteristics of articles by electronic tags. The relevant logistics infrastructure equipment and hand-held readers of the common logistics participants will read the EPC code contained in the electronic tags of the article and collect the information contained therein. The computer information collection software will correct the collected data, filter the noise data, and check its integrity, and then submit it to the upper management system.

2) Common logistics information management system: The system can carry out manual assistance or automatic management of common logistics and storage resources, transportation resources, distribution resources and human resources connected by the Internet of things, such as realtime scheduling management on logistics vehicles, dynamic analysis on commodity inventory, automatic calculation of logistics vehicle loading, selection of the best transportation route, and so on. 


\section{B. Suggestions for the Construction of Common Logistics System}

The government shall promote the formulation of Internet of things standards in the field of common logistics in a policy way, especially encourage the leading enterprises of Hunan rural logistics service demand-oriented to actively participate in the formulation of standards. In the formulation of the standards, the government should fully grasp the market demand, consider the future development trend of Internet of things technology, exert the government's standard and unified credibility within the industry, between industries between industries, and launch pilot projects. Beyond that, it shall increase the support for pilot enterprises, and nurture the development of Internet of things technology in the field of chain retail common logistics with good policies, social and cultural environment.

It is necessary to encourage the R \& D and application of Internet of things technology related to common logistics, formulate the corresponding incentive system, introduce excellent Internet of things technology researchers, fully mobilize Internet of things technology researchers' enthusiasm for scientific research, encourage them to innovate, vigorously support the transformation of scientific research results of Internet of things technology related to common logistics to a practical application, and increase the benefits of enterprises.

Rural logistics service demanders in Hunan, in accordance with their needs, should formulate practical logistics strategic goals for the application of Internet of things technology in common logistics, actively cooperate with government policies, increase the capacity for independent innovation, seek cooperation with research institutions, boldly implement the advanced common logistics Internet of things management system, and make enterprises more competitive.

\section{CONCLUSION}

The implementation of common logistics in the rural logistics industry in Hunan Province is an important way to rationalize logistics services in the rural logistics industry in Hunan Province. Through the construction of a common logistics system, rural logistics services demanders in Hunan Province can achieve the goal of reducing logistics infrastructure, logistics equipment and logistics vehicles while maintaining the level of logistics services unchanged or even improved.

\section{REFERENCES}

[1] Zhang Feng, Qin Liangliang, Cao Jie, Liu Yan. Research on the Logistics Joint Distribution Mode of Small and Medium-sized Chain Supermarkets. Transportation Enterprise Management. 2014 (12). (in Chinese)

[2] Miao Zhijuan. Research on the Application of Internet of Things Technology in Supply Chain of Retail Industry. Science \& Technology Vision. (in Chinese)

[3] Sun Xuejie. Research on the Application of Internet of Things Technology in Supply Chain of Logistics Industry [D]. Master's Thesis of Dongbei University of Finance and Economics. 2011, 12. (in Chinese) 